\title{
Saídas de emergência: autobiografias e espiritualidades trans
}

Emergency exits: autobiographies and trans spiritualities

\author{
Caio Jade Puosso Cardoso Gouveia Costa ${ }^{1}$
}

\begin{abstract}
Resumo: Este artigo apresentará as diferentes perspectivas religiosas e espirituais encontradas nos textos autobiográficos de Claudia Wonder, Roberta Close, Lorys Ádreon, Ruddy Pinho, Jorge Laffond e Jordhan Lessa. Veremos como suas expressões de sexo/gênero são acolhidas ou rejeitadas pelos sistemas religiosos da sociedade brasileira a partir de seus relatos. Analisaremos como espiritualidades singulares são criadas como respostas às exclusões e formatações impostas pelas religiões. Refletiremos sobre a dessacralização de expressões de sexo/gênero diversas como estratégia de exclusão social. Por fim, anunciaremos as religiosidades e espiritualidades trans como estratégias de reintegração e de ressacralização dos seres em relação à vida.
\end{abstract}

Palavras-chave: autobiografias trans; literatura brasileira; espiritualidade; estudos de gênero.

Abstract: This paper will present different religious and spiritual perspectives found in the autobiographical texts of Claudia Wonder, Roberta Close, Lorys Adreon, Ruddy Pinho, Jorge Laffond and Jordhan Lessa. We will see how their sex/gender expressions are accepted or rejected by the religious systems of Brazilian society in their narratives. We will analyze how unique spiritualities are created as responses to the exclusions and formattings imposed by the religions. We will reflect on the desacralization of diverse sex/gender expressions as a strategy of social exclusion. Lastly, we will propose trans spiritualities as strategies of reintegration and resacralization of the beings into life.

Keywords: trans autobiographies; brazilian literature; spirituality; gender studies.

\section{Abertura}

Este artigo é um desdobramento de um estudo mais amplo sobre expressões de sexo/gênero em autobiografias trans. Partiremos do entendimento de que tanto o conceito de sexo quanto o de gênero têm sido utilizados para indicar expressões de si e constituições físicas consideradas masculinas e/ou femininas no contexto da sociedade brasileira. Nesse sentido, proporemos o binômio sexo/gênero como conceito que abarca tanto as diversidades sexuais quanto as de gênero, a saber, as travestilidades, transexualidades, transgeneridades, homossexualidades e intersexualidades. A seleção das obras autobiográficas a serem analisadas neste

\footnotetext{
${ }^{1}$ Mestrando em Letras e graduado em filosofia pela Universidade de São Paulo
} 


\section{SACRILEGENS

artigo se deve à presença de tais diversidades de sexo/gênero em seus textos. Temos utilizado o conceito de autobiografia trans, que também encontramos no artigo de Amara Moira (2018), ao indicar relatos de pessoas que expressam diversidades de sexo/gênero. Optamos por utilizar esse termo da mesma maneira aberta e acolhedora com que tratamos as diversidades de sexo/gênero. Não temos a intenção de restringir ou de classificar expressões de sexo/gênero neste artigo. Nosso objetivo será percorrer os textos autobiográficos selecionados em busca das perspectivas religiosas e espirituais que cada autor apresenta.

Compreenderemos os conceitos de religiosidade e de espiritualidade de maneira aberta e intercambiável, de modo que abarque práticas singulares ou sínteses religiosas únicas e, por vezes, solitárias, construídas à margem de sistemas e de comunidades religiosas brasileiras. Veremos como tais rotas espirituais surgem como saídas de emergência para existências perseguidas ou excluídas por sistemas religiosos canônicos. Por fim, convocaremos vozes de ativistas indígenas brasileiros e cruzaremos suas perspectivas acerca do sagrado, da natureza e da espiritualidade, com as perspectivas espirituais das autobiografias trans analisadas. Dessa maneira, pretendemos sugerir a utilização do conceito de religiosidade ou espiritualidade trans para pensarmos práticas vividas às margens dos sistemas religiosos canônicos, mas que se alimentam desses sistemas criando experiências singulares, onde as diversidades de sexo/gênero diversas encontram rotas para suas realizações espirituais.

\section{Claudia Wonder}

Claudia Wonder foi uma multi-artista paulistana que trabalhou com música, performance, teatro e cinema. Foi militante por direitos, pela visibilidade e pelo reconhecimento das pessoas LGBTI² $^{2}$ brasileiras. Escreveu para a revista G Magazine, ao longo dos anos 2000, e alguns de seus textos foram compilados em uma publicação chamada Olhares de Claudia Wonder. Nesse livro, Wonder apresentou perfis de pessoas trans e transformistas, crônicas pessoais e reflexões teóricas sobre gênero e sexualidade. Seu trabalho jornalístico trouxe visibilidade e reconhecimento para diversas referências trans nos campos da arte, do mercado de trabalho e também da religião.

${ }^{2}$ Sigla para: Lésbicas, gays, bissexuais, travestis/transexuais/transgeneres e intersexo. 


\section{SACRILEGENS

O capítulo final de Olhares de Claudia Wonder traz reflexões sobre o budismo, o islamismo, o politeísmo grego e o cristianismo, cultura que fez parte da formação pessoal da artista desde a infância. Wonder aponta a bíblia como fonte de contradições onde encontramos tanto a condenação da homossexualidade, como em Levítico 20,13, quanto o enaltecimento do amor entre homens, como em Eclesiastes 4,9 (WONDER, 2008, p. 168). Nas culturas gregas e romanas, que influenciaram e que foram influenciadas pela cultura cristã, Wonder aponta que o amor entre homens era vivido e defendido por parte da sociedade grega (WONDER, 2008, p. 169), e que era perseguido e exterminado pela sociedade romana (WONDER, 2008, p. 177). Notemos, assim, como contradições são marcas comuns nas relações entre religiosidades e expressões de sexo/gênero. Dessa maneira, também encontramos contradições nas relações pessoais de Wonder com o cristianismo. Ao passo que a religiosidade cristã é apresentada pela autora como responsável pela condenação, perseguição e demonização da homo/transexualidade, também é revelada como fonte de acolhimento de sua experiência religiosa ao declarar sua "fé em Deus" (WONDER, 2008, p. 171).

Em culturas como a sulawesi, na Indonésia, existem mais de dois sexos/gêneros e cada qual possui um destino e função dentro de sua sociedade (WONDER, 2008, p. 178). Em contrapartida, os modelos ocidentais hegemônicos parecem pregar a existência de apenas dois sexos/gêneros, isto é, o homem e a mulher cisgêneros e heterossexuais, e condenar existências que fujam ao modelo binário, como podemos ver a partir da afirmação de Wonder: "não existe lugar para a androginia" (WONDER, 2008, p. 178). No ocidente, as diversidades de sexo/gênero não são reconhecidas como parte da natureza, diferentemente de outras culturas (WONDER, 2008, p. 178). Dessa maneira, diversidades como intersexualidades ou transgeneridades, como vividas pela própria autora, são condenadas à exclusão ou ao extermínio por não se enquadrarem nos moldes religiosos ocidentais. Segundo Wonder, assassinatos de pessoas de sexo/gênero diversos encontram respaldo em textos bíblicos (WONDER, 2008, p. 167). Ainda assim, há em Wonder, como em outros relatos que veremos adiante, a declaração de uma fé cristã. Tal fenômeno contraditório parece sinalizar que há a criação de sínteses espirituais singulares, ou seja, de processos espirituais íntimos que se alimentam dos modelos religiosos canônicos, ao passo que recusam aquilo que não lhes serve e tiram proveito do que lhes cabe. 


\section{SACRILEGENS

Wonder conta que desenvolveu uma religiosidade brasileira (WONDER, 2008, p.171), isto é, uma mistura entre o batismo católico, os passes nas sessões espíritas de mesa branca que sua mãe frequentava e os cultos protestantes da Igreja Universal do Reino de Deus aos quais seu pai a levava. Esse sincretismo parece reconfigurar a noção de religião para Wonder. Ao declarar que "o que importa mesmo é Deus, e não os dogmas" (WONDER, 2008, p. 170), Wonder parece responder aos ataques e às exclusões que pessoas de sexos/gêneros diversos sofrem, recusando as leis dos cânones religiosos, isto é, seus dogmas, mas reafirmando a importância da conexão espiritual com uma força criadora. Dessa maneira, as religiões canônicas parecem servir como fontes para a criação de rotas singulares de realização de sua espiritualidade.

\section{Roberta Close}

Nos anos 80, Roberta Close foi eleita como símbolo sexual ao posar para vários ensaios fotográficos eróticos. Sua imagem ficou impressa no imaginário da população brasileira e internacional através da frase do jornal estadunidense Weekly World News: "A mulher mais bonita do mundo é homem" (RITO, 1998, p. 33). No livro Muito prazer, Roberta Close, a jornalista Lucia Rito registrou, em terceira pessoa, memórias da modelo e atriz, e também transcreveu relatos autobiográficos coletados em entrevistas realizadas para o livro. Nos trechos finais de Muito prazer, Roberta Close, há um pequeno relato sobre a devoção da biografada por Santa Rita de Cássia. Roberta relata que o catolicismo lhe foi ensinado desde a infância através de sua mãe. Mas o respeito de Roberta pela igreja não foi correspondido pela comunidade católica, como podemos notar na seguinte passagem: "quando eu estou na igreja as pessoas ficam me olhando como se eu fosse incapaz de rezar" (RITO, 1998, p. 229). A sensação de exclusão que Roberta narra nos permite notar a estratégia católica de dessacralização da vida da artista. Roberta percebe que é vista como incapaz de realizar sua espiritualidade, como se suas expressões de sexo/gênero e seu meio de vida a impedissem de manifestar sua fé e partilhar uma experiência espiritual em comunidade.

Assim como Wonder, Roberta narra possuir uma fé cristã, mas não encontrar acolhimento por parte da comunidade religiosa, o que não a impediu de encontrar uma saída para sustentar sua espiritualidade. Quando Roberta afirma: “prefiro rezar 


\section{SACRILEGENS

comigo mesma" (RITO, 1998, p. 229), a artista cria uma rota espiritual que contorna as adversidades encontradas em relação à comunidade católica que costumava frequentar. Roberta recria uma conexão íntima e mais direta com suas forças criadoras através de rezas solitárias. Notemos como tal rota de fuga assemelha-se ao caminho de Wonder descrito anteriormente, onde a autora se afasta do sistema religioso canônico, mas conserva sua fé recriando, assim, sua religiosidade. Se a igreja católica não pode proporcionar o conforto que Roberta Close esperava (RITO, 1998, p.229), a artista fez de si mesma o templo para a sacralização de sua espiritualidade.

\section{Lorys Ádreon}

Não temos muitas informações sobre Lorys Ádreon além de sua autobiografia. Nascida na Espanha e criada no Brasil no estado do Amazonas, a vida de Lorys está descrita na obra Meu corpo, minha prisão: autobiografia de um transexual como um chamado de interlocução sobre suas experiências e sofrimentos vividos ao longo de seus 25 anos de idade. Dentre os relatos de Lorys, encontramos a história de um grande amor com um indígena chamado Oitameno, da região do alto do rio Madeira em Manaus. Gostaríamos de destacar dois breves relatos de Meu corpo, minha prisão nos quais poderemos vislumbrar o papel do cristianismo nas reflexões de Lorys sobre si mesma, e as características da visão de Oitameno acerca da espiritualidade de Lorys.

Após a tentativa de suicídio de Lorys, Oitameno assume a responsabilidade dos cuidados para a recuperação da jovem. Lorys, ciente da paixão exacerbada de Oitameno por ela, resolve questioná-lo para certificar-se dos sentimentos do rapaz, visto que, aos seus olhos, seria estranho um rapaz se apaixonar por uma pessoa transexual quando poderia escolher uma mulher "normal” (ÁDREON, 1985, p. 68). Diante do ultimato de Lorys, Oitameno traça um breve relato das razões de seu amor. Interessa-nos particularmente o caráter afetivo-espiritual que Oitameno aponta como sendo a principal virtude de Lorys (ÁDREON, 1985, p. 69). O teor da espiritualidade de Lorys foi percebido por Oitameno através do cuidado que a jovem dedicou a uma senhora mestiça, de nome Natália, que foi rejeitada pela família ao manifestar a lepra. Ao ver que Natália havia sido isolada em uma habitação distante de sua família, Lorys dedicou-se a alimentar e a cuidar de Natália ouvindo suas histórias e conversando com a senhora até a data de sua morte. Oitameno, nascido na floresta, 


\section{SACRILEGENS

em uma comunidade indígena do povo Juma, traduziu como espiritualidade as qualidades de sensibilidade e de afeição de Lorys por Natália. Nesse sentido, Oitameno chama de espiritualidade o caráter de Lorys ao revelar-se uma pessoa que se dedica a outra sem colocar seus preconceitos ou seus medos acima da vulnerabilidade daquela que está necessitada de cuidados. Comparemos essa noção de espiritualidade com aspectos do cristianismo de Lorys em uma oração em que a jovem pergunta ao "Senhor Deus" porque havia acabado de ser violentada sexual e moralmente por um grupo de rapazes. Segue o trecho:

Perguntava ao Senhor Deus por que havia permitido um 'espinho' tão doloroso a transpassar minha carne, mas não obtinha nenhuma resposta porque Ele estava nos céus invisíveis, e eu miserável ser, fenômeno aberrativo de Sua Criação, me arrastava na baixeza da Terra, esmagado sob o peso da imperfeição e da anormalidade (ÁDREON, 1985, p. 107).

A visão de espiritualidade de Oitameno está ligada às ações de Lorys em relação à Natália, isto é, está ligada à vida terrena e às relações interpessoais de amparo, auxílio e conexão com o outro. Já a perspectiva de Lorys descreve uma separação entre a vida terrena, lugar da imperfeição e do erro, e uma existência oposta, invisível, celeste, criadora e silenciosa, que seria responsável por sua vida. Essa visão cristã revela uma sensação de desintegração da criatura com seu criador, tanto quanto revela uma desvalorização de si ao reconhecer-se como ser miserável e aberrativo. Dessa maneira, Lorys parece indicar um estado de desolação e de desamparo em relação ao sagrado. O sistema religioso cristão, herdado por Lorys de sua família, reforça sua miséria e seu deslocamento social, no lugar de servir-lhe de conforto em um momento crítico de desespero. Podemos notar que a sensação de Lorys em relação à religiosidade cristã delineia um campo de solidão e de exclusão semelhante a outros relatos trans já discutidos. Já a percepção de Oitameno revela em Lorys uma espiritualidade afetiva e comunitária, integrada com o outro e com a vida. Retomaremos a perspectiva de Oitameno sobre Lorys no final deste artigo, quando veremos outras perspectivas indígenas que contribuirão para a formação do que chamaremos de religiosidades ou espiritualidades trans.

\section{Ruddy Pinho}

Ruddy trabalha até hoje como cabeleireira no Rio de Janeiro. Sua primeira autobiografia, intitulada Liberdade ainda que profana, foi lançada em 1998 e conta 


\section{SACRILEGENS

sua trajetória profissional, seus trabalhos artísticos no teatro, episódios de sua vida pessoal e reflexões sobre suas condições de gênero e de sexualidade. O oitavo capítulo de seu livro é dedicado à religião e revela a importância do candomblé em sua vida. Ruddy relata que desde a infância sentia em seu corpo e em sua mente manifestações espirituais (RUDDY, 1998, p. 71) e chegou a conhecer o kardecismo e a umbanda, porém não os seguiu. A autora conheceu o candomblé através do contato profissional com Maria Bethânia e com outras artistas baianas, mas foi através de sua funcionária, Dona Lina, que Ruddy encontrou a casa de candomblé na qual foi iniciada em 1972. Ruddy relata que não sofreu preconceito sexual nessa casa, mas sofreu estranhamento por parte da comunidade candomblecista por possuir pele branca, por ser uma pessoa pública com fama e por viver em Ipanema, um bairro de classe média alta da cidade do Rio de Janeiro. Ruddy aponta que a recepção da comunidade candomblecista mudou quando a autora completou sua obrigação de sete anos de iniciada em 1979. Ao receber o posto de Babalorixá, cargo de maioridade dentro do candomblé designado a pessoas masculinas, Ruddy passou a não ser mais vista como oportunista (RUDDY, 1998, p. 72).

Ao cumprir as obrigações de 14 anos de iniciada, Ruddy já havia vivido mudanças sociais e corporais de gênero, e teve sua transgeneridade reconhecida e apresentada à comunidade candomblecista ao ser renomeada como Ialorixá, cargo feminino de maioridade, no ano de 1986 pelas mãos de Pai Paulo da Pavuna. Levando em conta que o candomblé é um culto brasileiro matriarcal, vemos que o caso de Ruddy é um marco de aceitação da diversidade de expressões de sexo/gênero pela religião. Como podemos ver no artigo Resistências e rejeições nas vivências de pessoas trans no candomblé da Bahia (DIAS; COLLING, 2018), a receptividade às diversidades de sexo/gênero nos terreiros de candomblé não são tão comuns. O posto de Ialorixá conferido a Ruddy designou-lhe um cargo máximo de prestígio e de sacerdócio que, literalmente, significa tornar-se mãe do sagrado. Ruddy passou por uma transição dentro do candomblé e ainda que não tenha mencionado os possíveis preconceitos pelos quais passou, os percebemos nas entrelinhas de suas declarações. A autora diz não dever respeito e obrigações a mais ninguém além seu sacerdote Pai Paulo da Pavuna. A escolha de Pai Paulo ao aceitar Ruddy tal qual ela é, sem querer conformá-la a outro modelo de sexo/gênero, nos parece uma posição que prioriza a essência da espiritualidade da autora, em vez de atender às normas da sociedade. Ruddy diz que Pai Paulo acreditou nela e em sua responsabilidade com o sagrado 


\section{SACRILEGENS

mesmo que tivesse uma "vida social tão distante da maioria dos chefes religiosos" (RUDDY, 1998, p. 72). Assim sendo, as diferenças de sexo/gênero e de meios de vida entre Ruddy e os demais sacerdotes não impediram Pai Paulo de reconhecê-la em sua feminilidade e de acolhê-la por inteiro.

Ruddy descreve seu carinho e sua dedicação pelo candomblé e relata segui-lo com muita fé (RUDDY, 1998, p. 72), o que indica que a autora se realiza espiritualmente dentro da comunidade candomblecista. Seu relato é o primeiro deste estudo que encontra algum reconhecimento comunitário de uma espiritualidade integrada à condição de sexo/gênero da pessoa. Mesmo assim, encontramos em seu livro traços das marcas de exclusão promovidas por culturas religiosas canônicas. No próprio título, Liberdade ainda que profana, podemos notar o lugar de dessacralização ao qual as pessoas de sexo/gênero diversos são destinadas; porém a autora parece declarar sua liberdade como profana no sentido de uma reviravolta, isto é, se opondo ao que é sagrado para a perspectiva das religiões canônicas. Nesse sentido, a sacralidade da liberdade profana da autora pode ser interpretada como uma escapatória à rota de não-liberdade projetada pela cultura hegemônica para sua existência de sexo/gênero diversa.

\section{Jorge Laffond}

Bofes \& Babados, autobiografia de Jorge Laffond lançada em 1999, apresenta breves relatos de vida e depoimentos de convidados, entremeados por fotos pessoais e recortes de jornais referindo-se à polêmica da revelação de um caso amoroso com um famoso jogador de futebol. Laffond narra episódios da sua infância, da carreira artística e também experiências e aspectos de sua sexualidade, tema que parece ser um dos motores de seu livro. À primeira vista, o livro parece um almanaque de jogos e de fofocas dedicadas aos telespectadores que Laffond conquistou ao longo de sua carreira, principalmente através da personagem Vera Verão, uma travesti caracterizada pela lubricidade e pelo conflito. Como aparente contraponto temático, o primeiro relato de Laffond no livro narra a importância da espiritualidade em sua vida. Laffond conta que frequentou dois centros espíritas de umbanda antes de dedicar-se ao candomblé, religião na qual encontrou realização e acolhimento.

Ao longo do livro podemos ver como Laffond cruza a espiritualidade candomblecista com suas expressões de sexo/gênero. Ao referir-se aos "mistérios das 


\section{SACRILEGENS

Iabás” (LAFFOND, 1999, p. 63), isto é, mistérios de divindades iorubanas femininas, Laffond declara carregar tais segredos espirituais, que teriam influenciado suas expressões de sexo/gênero inclusive para a criação de seu alter ego, Vera Verão. O contexto de sua declaração é o campo das expressões de gênero e de sexualidade. "Eu, como homem, tive os homens que quis" (LAFFOND, 1999, p. 63) é a frase que antecede a reflexão de Laffond sobre os mistérios de sua personalidade "multifacetada" e "surrealista" (LAFFOND, 1999, p. 63). Ademais, Laffond considera seu caráter como uma "luz própria" (LAFFOND, 1999, p. 63) e posiciona-se diante da vida de maneira muito otimista e batalhadora, o que parece estar atribuído ao fato de reconhecer-se como uma pessoa "muito espiritualista" (LAFFOND, 1999, p. 63). Nesse sentido, podemos supor que suas experiências espirituais e religiosas no candomblé tenham sido acolhedoras para suas expressões de sexo/gênero.

Ao reconhecer-se como reflexo das Iabás, Laffond revela uma característica da tradição candomblecista, que consiste no fato das forças femininas e masculinas regerem as vidas das pessoas independentemente de seus sexos/gêneros. Isto é, uma pessoa designada como homem pela sociedade pode ser regida por uma divindade feminina, e uma pessoa designada mulher pode ser regida por uma divindade masculina. Essas forças manifestam-se nas personalidades das pessoas, o que parece criar relações mais próximas com as diversidades sexuais e de gênero. Assim, o mistério mencionado por Laffond anuncia-se como espaço espiritual integrador para expressões de sexo/gênero frequentemente condenadas e dessacralizadas por outras religiões.

\section{Jordhan Lessa}

As vivências religiosas de Jordhan Lessa narradas no capítulo final de seu livro Eu trans, a alça da bolsa, relatos de um transexual, publicado em 2014, assemelham-se ao sincretismo religioso experimentado por Wonder. Lessa cresceu no cruzamento de experiências católicas e umbandistas, e também frequentou terreiros de candomblé e igrejas protestantes ao longo de sua vida. Em suas buscas, se apaixonou pela doutrina espírita kardecista, que lhe satisfez, racional e emocionalmente, as indagações sobre a vida (LESSA, 2014, p.132). Lessa frequentou diferentes espaços religiosos onde pode adquirir conhecimentos e aprendizagens tanto espirituais quanto sociais, mas não se integrou a nenhuma tradição. $\mathrm{O}$ autor 
conta que se decepcionou com o catolicismo quando criança, pois descobriu que a hóstia não lhe conferia poderes mágicos (LESSA, 2014, p.127); e abandonou a igreja católica ao estudar sua atuação na santa inquisição e na escravidão dos povos africanos. Posteriormente, Lessa deixou a umbanda ao perder seu zelador, que foi assassinado. Deixou o candomblé quando percebeu que as pessoas acabavam pagando caro para obter algo que já estava dentro delas (LESSA, 2014, p.131). Enfim, deixou a igreja cristã contemporânea, uma igreja fundada em 2006 por dois pastores homossexuais que têm a inclusão da diversidade como bandeira cristã. Apesar do acolhimento que o autor sentiu nessa igreja, percebeu que mais um ciclo havia terminado (LESSA, 2014, p. 135). Os caminhos de Lessa parecem tê-lo levado a encontrar em si mesmo a fortaleza que buscava dentro dos espaços religiosos que frequentou. Nas palavras do autor: "ao entender que não preciso de religião alguma, fortaleci a minha fé" (LESSA, 2014, p. 136). Seu posicionamento diante das religiões aproxima-se da atitude de Wonder e de Close na medida em que se alimenta de diversas fontes e recria em si mesmo sua própria versão de espiritualidade. Essa síntese espiritual parece ser uma característica, brasileira e trans, que surge a partir de trânsitos impulsionados por despertencimentos, isto é, trânsitos que expressam buscas por lugares que não existem no mundo tal qual está dado, a saber, um mundo que apaga os rastros das expressões de sexo/gênero diversas.

Lessa narra que a primeira vez que viu pessoas "gays" foi dentro das reuniões da umbanda que frequentava com sua mãe. Essas pessoas pareciam alegres e festivas nos encontros, além de possuírem uma "linguagem própria” (LESSA, 2014, p. 128). O candomblé, posteriormente, também colocou o autor em contato com "muitas pessoas diferentes das que havia conhecido" (LESSA, 2014, p. 131) e o levou a partilhar da linguagem dessas pessoas ao se relacionar com uma senhora candomblecista. A partir do que vimos no relato de Ruddy e de Laffond, notamos no relato de Lessa a repetição de um fenômeno de inclusão da diversidade de sexo/gênero pelas religiões de matrizes africanas, como a umbanda e o candomblé. Em contrapartida, algumas relações de Lessa com cristianismos protestantes ou evangélicos tradicionais se assemelham às de Wonder e de Ádreon com cristianismos católicos. Lessa deparou-se nessas igrejas com tentativas de exorcizá-lo e de condenálo ao inferno (LESSA, 2014, p. 133), dado que tais cristianismos têm como lei professar a rejeição de diversidades de sexo/gênero. Lessa também aponta que falsas inclusões e falsos afetos são utilizados como estratégias de incorporação das 


\section{SACRILEGENS

diversidades de sexo/gênero pelas igrejas (LESSA, 2014, p. 133), a fim de formatar seus seguidores segundo os modelos da cisgeneridade e da heterossexualidade.

Lessa, enfim, aponta para o amor como centro de valor para a espiritualidade (LESSA, 2014, p. 137). Isto é, ele indica o que poderíamos chamar de um sentimento que se projeta sobre os outros e sobre o mundo buscando relações cooperativas e nãohierárquicas. Assim sendo, nos aproximamos da visão de Oitameno sobre a afetivo espiritualidade de Lorys Ádreon. Ao negar a necessidade de uma religião, Lessa parece afastar-se dos dogmas que sistematizam as religiões, como também se afasta ou é afastado das comunidades religiosas. Encontramos em Lessa, como em Wonder e em Close, o caminho da solidão e da singularidade como saída para a realização da espiritualidade. A seguir, pensaremos essas rotas espirituais íntimas como saídas de emergência, isto é, caminhos criados à margem dos sistemas religiosos tradicionais. Caminhos esses que se caracterizam como sínteses de diferentes culturas espirituais e que permitem a criação de rotas de fuga para outros mundos, onde ser quem se é se torna uma experiência possível, completa e sagrada.

\section{Saídas para outros mundos}

Vimos que quase todas as autobiografias trans selecionadas relataram exclusões, desconfortos ou abandonos religiosos sofridos por conta das diversidades de sexo/gênero expressadas. Também notamos que, mesmo com as adversidades, seus autores recriaram caminhos singulares e por vezes solitários para realizar suas espiritualidades, como vimos em Claudia Wonder, em Roberta Close e em Jordhan Lessa. No caso de Lorys Ádreon, notamos que a perspectiva indígena de Oitameno operou como contraponto à desvalorização de si que Ádreon desenvolveu a partir de suas heranças cristãs. Também notamos que instituições religiosas de matriz africana proporcionaram a Ruddy Pinho e a Jorge Laffond certos reconhecimentos de suas expressões de sexo/gênero. Assim, a busca pela sacralização das diversidades de sexo/gênero pode ser pensada como ponto em comum às autobiografias estudadas.

Apontamos que, apesar das segregações, das desvalorizações ou das exclusões religiosas relatadas nas autobiografias, seus autores parecem digerir e reaproveitar os cânones religiosos brasileiros com os quais tiveram contato para, então, recriar rotas de realização espiritual onde a diversidade de suas expressões de sexo/gênero pudesse ser acolhida e vivenciada integralmente. Nesse sentido, gostaríamos de 


\section{SACRILEGENS

abordar comparativamente algumas perspectivas indígenas brasileiras sobre a sacralidade da vida para que pensemos as religiosidades ou espiritualidades trans como sacralização das diversidades de sexo/gênero e como movimento de reintegração dos seres com a totalidade do mundo. Comecemos analisando uma resposta de Ailton Krenak, ativista indígena nascido na região do médio Rio Doce em Minas Gerais, ao ser questionado em uma entrevista se praticava sua religião:

Eu pratico. Eu acho que nossa tradição é muito diferente, por exemplo, da dos cristãos, para quem a ideia de praticar uma tradição ou uma religião está vinculada a um conjunto de normas e condutas. Para nós isso não existe. Eu não preciso ir a um templo, não tenho que ir a uma missa. Eu me relaciono com o meu criador; me relaciono com a natureza e com os fundamentos da tradição do meu povo (KRENAK, 2015, p. 83).

A declaração de Krenak pode nos ajudar a desenvolver a ideia de singularidade das espiritualidades que analisamos anteriormente. Krenak traça contornos à margem das religiões canônicas e sugere saídas a outros mundos possíveis ao dizer que sua prática é uma relação direta e integrada com seu criador, com a natureza e com a tradição de seu povo. De certa maneira, as espiritualidades apresentadas também parecem anunciar relações mais diretas com suas forças criadoras e mantenedoras da vida, uma vez que não seguem à risca os cânones religiosos, mas se alimentam deles produzindo sínteses, muitas vezes, solitárias. Relatos como os de Wonder, de Close e de Lessa são exemplos de conexões diretas com as forças criadoras e mantenedoras da vida, pois, ao recusarem ou ao serem recusados pelas religiões canônicas, acabam por preferir ter suas fés íntimas como condutores espirituais de suas existências. Uma diferença importante, entre a perspectiva de Krenak e a dos autores que analisamos, está na possibilidade de uma experiência espiritual comunitária que a perspectiva indígena manifesta, mas que se encontra frequentemente interditada nas autobiografias trans estudadas.

Em uma entrevista, Kaká Werá declara a Daniel Munduruku, ambos ativistas indígenas, que o reconhecimento da vida como sagrada é um dos aspectos essenciais da espiritualidade indígena3. Segundo tais perspectivas, que são comuns a diversos grupos indígenas, a vida é tudo que existe, é a totalidade dos acontecimentos e dos seres, sem subdivisões ou categorias inorgânicas. Há vida nas pedras, no vento e na água como há nos animais e nas plantas. Assim sendo, tudo é sagrado e tudo é espírito, pois tudo é vivo. Perspectivas como essa reconhecem os seres humanos

3 Disponível em: https://www.youtube.com/watch?v=XgAmIv3Jqzs. Acesso em: 24 mai. 2020. 


\section{SACRILEGENS

como seres integrados ao mundo, como podemos ver no trecho a seguir, em outro texto de Ailton Krenak:

Fomos nos alienando desse organismo de que somos parte, a Terra, e passamos a pensar que ele é uma coisa e nós, outra: a Terra e a humanidade. Eu não percebo onde tem alguma coisa que não seja natureza. Tudo é natureza. O cosmos é natureza. Tudo em que eu consigo pensar é natureza (KRENAK, 2019, p. 14).

Considerando essa perspectiva, propomos uma reflexão sobre as diversidades de sexo/gênero como partes da natureza e da vida, ou seja, como expressões sagradas de forças criadoras que se manifestam sobre o mundo. Em vez de considerar tais diversidades como erros a serem eliminados, perspectiva essa que vimos, por exemplo, estar mais explícita nos relatos de Ádreon e de Lessa ao mencionarem suas relações com cristianismos, sugerimos perceber tais diversidades como expressões da natureza. Alimentando-nos das perspectivas indígenas mencionadas, podemos localizar as diversidades de sexo/gênero integradas ao todo da vida ou do mundo e, portanto, ao sagrado. Com isso, gostaríamos de sugerir que as saídas singulares anunciadas nas autobiografias deste estudo indicam movimentos de sacralização de existências que recusaram ou que foram recusadas, em alguma medida, por sistemas religiosos brasileiros.

Por fim, propomos chamar de religiosidades ou espiritualidades trans as experiências de sacralização de si mesmo e de integração de si com a totalidade da natureza, a contrapelo de comunidades e de sistemas religiosos que, por vezes, excluem, demonizam e segregam pessoas que expressam diversidades de sexo/gênero. Por fim, propomos que as religiosidades ou espiritualidades trans representam resistências criativas de ressacralização de vidas maltratadas e deslocadas pelos cânones religiosos que se impõem como verdades únicas e sacras definindo sexo e gênero segundo as normas cisgêneras e heterossexuais. Dessa maneira, as espiritualidades trans podem ser vistas como saídas de emergência, criadas a partir de mundos excludentes, que rumam a outros mundos possíveis onde a diversidade de sexo/gênero possa ser parte constituinte da totalidade sagrada da vida.

\section{Bibliografia}

ÁDREON, Lorys. Meu corpo, minha prisão: autobiografia de um transexual. Rio de Janeiro: Marco Zero, 1985. 


\section{SACRILEGENS \\ Revista Discente do Programa de \\ Pós-graduação em Ciência da Religiào da UFJF}

DIAS, Claudenilson; COLLING, Leandro. Resistências e rejeições nas vivências de pessoas trans no candomblé da Bahia. Revista Ex Aequo, $\mathrm{N}^{\circ} 38$, 2018, pp 95-110. Disponível em: http://dx.doi.org/10.22355/exaequo.2018.38.07. Acessado em: 26 mai. 2020.

KRENAK, Ailton. Receber Sonhos. Em: COHN, Sergio (Org.). Encontros. Rio de Janeiro: Azougue, 2015.

KRENAK, Ailton. Ideias para adiar o fim do mundo. São Paulo: Companhia das Letras, 2019.

LAFFOND, Jorge. Bofes \& Babados. Rio de Janeiro: Star Brazil CC\&P, 1999.

LESSA, Jordhan. Eu Trans: a alça da bolsa, relatos de um transexual. Rio de Janeiro: Metanoia, 2014.

MOIRA, Amara. O que nos dizem as autobiografias trans? Em: Suplemento Pernambuco, 2018. Disponível em: https://www.suplementopernambuco.com.br/artigos/2053-0-que-nos-dizem-asautobiografias-trans.html. Acessado em: 17 jun. 2020.

RITO, Lucia. Muito prazer, Roberta Close. Rio de Janeiro: Rosa dos Tempos, 1998.

RUDDY. Liberdade ainda que profana. Rio de Janeiro: Razão Cultural, 1998.

WONDER, Claudia. Olhares de Claudia Wonder: crônicas e outras histórias. São Paulo: Summus editorial, 2008.

Recebido em: 26/05/2019

Aceito em: 23/06/2020 